\title{
Shuttle repair a mixed blessing
}

\section{Washington}

SOLAR physicists are to be the chief beneficiaries of the first attempt by the National Aeronautics and Space Administration (NASA) to use the space shuttle for repairing a satellite in orbit. If this week's mission goes according to plan, astronauts will rendezvous with the crippled Solar Maximum satellite, which failed only months after its 1980 launch, and replace several defective components that are to blame for instrument malfunctions and the satellite's failure to keep an accurate lock on the Sun.

If the repairs - which will require the astronauts to spend two work days outside the shuttle - are successful, the satellite will once again provide solar physicists with data that are not available from ground-based observatories. The Solar Maximum satellite carries seven instruments, including ultraviolet, gamma-ray and hard X-ray detectors that measure radiation from the hottest regions of solar activity. These short wavelengths, which correspond to plasma temperatures of as much as 20 million kelvin, are cut out by gases in the Earth's atmosphere; groundbased observatories can "see" plasma temperatures only up to roughly 10,000 kelvin.

Although the satellite was designed principally to provide data on solar flares during the 1980 peak of solar activity, solar physicists say that there will still be much for Solar Max to look at. Solar flares are less frequent now; but the largest flares tend to occur during the declining part of the cycle, as now. The satellite will also provide data on active regions of the Sun in general and on other forms of activity, such as solar prominences and ejections of mass from the Sun. Successful repair of Solar Max's coronagraph - in effect, an optical telescope - may provide the added bonus of pictures of Halley's comet in 1986 as it passes near the Sun.

Only three of the instruments are at present providing data - a gamma-ray detector, a hard X-ray burst detector and an instrument that measures total solar output (which has demonstrated variability in what had been thought to be the constant solar constant). The failure of the satellite's pointing mechanism, which is supposed to keep it locked onto the Sun, has been the principal source of trouble; the satellite is now spinning up to $10^{\circ}$ off axis in what NASA officials euphemistically term the "coarse pointing mode". The other instruments depend more critically on accurate alignment with the Sun; what is more, the coronagraph and the $\mathrm{X}$-ray polychromator are suffering from additional malfunctions which the astronauts will attempt to correct.

The total cost of the repair mission, according to NASA's Goddard Space
Flight Center, will be $\$ 45-50$ million, which includes the cost of developing special tools and of training the astronauts. The Solar Max originally cost $\$ 75$ million; Goddard officials say its replacement cost today would be $\$ 240$ million. These figures do not however, include the cost of the shuttle launch.

Although the solar physics community generally supports the repair mission, some space scientists question the economics. Herbert Bridge, for the Center for Space Research at Massachusetts Institute of Technology, said last week, "I'm sure if they did a realistic cost estimate, the true figure would be a couple of hundred million. How you justify this I just don't know." Bridge did acknowledge the value of the repair mission as "a training exercise".

Other space scientists seem more genuinely enthusiastic. The solar division of the American Astronomical Society passed a resolution of support and Andrea Dupree of the Smithsonian Astrophysical Observatory said that both the immediate pay-off for solar physics and the development of repair techniques that can be used on other scientific satellites "are of equal weight".

The repairs, if successful, are expected to hold for between one and three years. As part of the operation, the satellite will be lifted from its current orbit of 270 nautical

\section{Plagiarism accusations at Stanford}

A FACULTY ethics committee at Stanford University Medical School is investigating charges that the chairman of the Department of Medicine, Dr Kenneth Melmon, plagiarized material from a medical textbook.

A chapter written by Dr Melmon for Textbook on Endocrinology contains 15 pages verbatim from $T$ The Pharmacological Basis of Therapeutics. Dr Melmon said he believed the editor of the endocrinology text had permission from the publishers of the pharmacology text to use the material.

Although both books were published in 1979 , it was only last month that Macmillan Publishing Company of New York complained to Stanford that its pharmacology book had been plagiarized.

Dr Melmon is "bewildered, in shock and dismayed" by the accusations, said Stanford law professor Jack Friedenthal, who has volunteered legal services to the physician. "This is one of those agonizing, unfortunate things that could happen to any one of us as we all use one another's work in legitimate ways."

Dr Melmon's problem is that the only witness to his side of the story, Robert $\mathrm{H}$. Williams, is dead. According to Dr Melmon, he included the section on miles to 290.

Future solar observations from space are now being planned but will be limited compared with Solar Max's capabilities. Spacelab 2, now scheduled for launch during 1985, will carry instruments to observe the "quiet Sun"; Spartan number two - a scientific payload that will coorbit with a future shuttle flight - will measure the solar wind close to the Sun; and the large Solar Optical Telescope, a very high resolution, one-and-a-quarter metre telescope, is to be flown from the shuttle around 1990.

The Solar Max repair mission is a first for NASA, and will involve a number of untried procedures. The trickiest part may be the initial grab of the satellite, which is spinning at about one degree per second. After the shuttle approaches to within 200-300 feet, astronaut George Nelson will fly out using the jet backpack tested during the last shuttle flight. Nelson will approach the satellite in an arc, matching its spin, then grab onto it and halt the spin using his backpack thrusters. The shuttle will then approach and grab the satellite with its remote manipulator arm. Over the next two days, astronauts will repair the coronograph's electronics module and the satellite pointing system and install a baffle on the $\mathrm{X}$-ray polychromator, which has been plagued by solar plasma flowing into a vent port and saturating the instrument. If the operation fails, the entire satellite will be loaded into the shuttle cargo bay and returned to Earth.

Stephen Budiansky

pharmacology at Dr William's urging. Dr Williams, the editor of the textbook, said he would arrange to get the necessary permission, and later telephoned to say that permission had been granted.

Dr Williams has since died of a heart attack, and Dr Melmon has no proof to support his contention that permission was sought and granted.

None of the editors who worked on the pharmacology text recall or have records of anyone asking permission to use the material in question.

According to $\mathrm{Mr}$ Friedenthal, Dr Melmon would have nothing to gain by plagiarizing the material. Sceptics say that people who plagiarize seldom think they will get caught.

A medical school standing committee on ethical scientific performance is looking into the matter and will make a report to Stanford president Donald Kennedy in about a week. It must decide if Dr Melmon is telling the truth and what is to be done about the charges from the publisher.

"This has been very painful to Melmon", Mr Friedenthal said. "There is a cloud over his head and suddenly his fine reputation has been dragged through the mud." Sandra Blakeslee 